\title{
Soft Tissue Response to the Presence of Polypropylene-G-Poly(ethylene glycol) Comb-Type Graft Copolymers Containing Gold Nanoparticles
}

\author{
Derya Burcu Hazer, ${ }^{1}$ Baki Hazer, ${ }^{2}$ and Nazmiye Dinçer ${ }^{3}$ \\ ${ }^{1}$ Department of Neurosurgery, Faculty of Medicine, Mugla University, 48000 Muğla, Turkey \\ ${ }^{2}$ Department of Chemistry, Zonguldak Karaelmas University, 67100 Zonguldak, Turkey \\ ${ }^{3}$ Department of Pathology, Atatürk Education and Research Center, 06010 Ankara, Turkey
}

Correspondence should be addressed to Baki Hazer, bhazer2@yahoo.com

Received 31 May 2011; Accepted 27 September 2011

Academic Editor: Hicham Fenniri

Copyright ( $) 2011$ Derya Burcu Hazer et al. This is an open access article distributed under the Creative Commons Attribution License, which permits unrestricted use, distribution, and reproduction in any medium, provided the original work is properly cited.

The aim of this study is to evaluate the soft tissue response of the pure and Au-embedded PPg-PEG. PP-g-PEG2000, PP-g-PEG4000, Au-PP-g-PEG2000, and AuPP-g-PEG4000 were obtained via chlorination of polypropylene and polyethylene glycol in the presence of a base with a "grafting onto" technique. Solvent cast films of these four copolymers with PP as a control group were embedded into five different rats. After 30 days of implantation, microscopic evaluation of inflammation and SEM analysis were done. PP had the most intense inflammatory reaction among the other polymers. PP-PEG block copolymers with high molecular weight and gold-nanoparticles-embedded ones revealed mild inflammatory reaction independently. SEM assessment revealed punched hole-like defects on the surface of all polymer samples except for PP. Graft copolymers with PEG, especially Au-attached ones, have favorable soft tissue response, and inflammatory reaction becomes milder as the number of PEG side chains increases.

\section{Background}

Polypropylene (PP) is a well-known hydrophobic polymer which has good mechanical properties and easy processing with low cost and excellent recyclability $[1,2]$. Because of its good film and fiber properties, it has found widely medical applications. However, in order to obtain a better in vivo biocompatibility, hydrophilic groups can be introduced into this polymer to overcome its hydrophobic character via postpolymerization reactions [3]. These newly formed polymers are named as amphiphilic block copolymers. Grafting reactions of the hydrophilic segments with a hydrophobic chain can be performed in three routes [4-6]: "grafting from," "grafting through," and "grafting onto" leading to comb- or brush-type graft copolymers [7-11]. Brush-type graft copolymers consist of a linear backbone with a high grafting density of side chains (usually one side chain per repeat unit of the backbone). Comb-type graft polymers consist of a main polymer chain, the backbone with one or more side chains attached to it through covalent bonds, and the branches. The total molar mass and the properties of combtype graft are determined by the backbone length, grafting density, and side chain length. Grafting onto method of polymerization was explained in our previous work in detail [12]. Block copolymers having a poly(ethylene glycol) (PEG) comprise a special and interesting category since PEG is a crystalline, neutral, biocompatible material with hydrophilic properties [13-15]. They have a unique molecular structure containing parts with both hydrophobic and hydrophilic character [16-18]. Since PEG overcomes the hydrophobic effect of the PP, the diversity of in vivo application of PPPEG will be expanded. To our knowledge, experimental studies concerning the in vivo properties of low and PP-PEG block copolymers with high molecular weight have not been studied previously.

Another attractive research field in biomaterials is polymer-stabilized nanoparticles, especially metal nanoparticles such as gold and silver [19-27]. In our previous study, we 
have already pointed out antimicrobial effects of $\mathrm{Au}$ and $\mathrm{Ag}$ nanoparticles embedded [28] into the PP-g-PEG amphiphilic polymers. We have also studied the in vivo and in vitro biocompatibility of Au-embedded copolymer samples [28-31]. Au-nanoparticle-embedded biodegradable polymers were found to cause less inflammation when compared to pure type [29]. The synthesis, spectroscopic characterization, and antibacterial activity of metal nanoparticles embedded in the PP-g-PEG amphiphilic comb-type graft copolymers were studied by our research group, previously [28]. According to these recent data, we think that this copolymer can be a promising biomaterial and we have planned a new study based on in vivo behavior of gold-nanoparticle-attached PP-g-PEG and pure PP-g-PEG film samples. These data were also supported with SEM assessment as well as their histology.

\section{Materials and Methods}

2.1. Materials. PEG2000, PEG4000, chlorinated PP (PP-Cl), $\mathrm{NaH}$, and the solvents were all purchased from Aldrich and used without further purification.

2.1.1. Synthesis of Pure and Gold-Nanoparticles-Embedded PP-G-PEG Amphiphilic Graft Copolymers. The synthesis of PP-g-PEG2000, pure PP-g-PEG4000, Au-nanoparticles-embedded PP-g-PEG2000, and Au-PP-g-PEG4000 was explained in our previous study in detail $[12,28]$. Briefly, the Williamson-ether-synthesis-like reaction between PEG and $\mathrm{PP}-\mathrm{Cl}$ was performed in THF solution in the presence of sodium hydride. A typical endcapping reaction was performed as follows: PEG-2000 (5.0 g, $2.5 \mathrm{mmol})$ and PP-Cl $(1.43 \mathrm{~g}, 1.0 \mathrm{mmol} \mathrm{Cl})$ were mixed and dissolved in dry THF $(10 \mathrm{~mL})$. NaH $(0.12 \mathrm{~g}, 5 \mathrm{mmol})$ was added to the solution, and the reaction mixture was stirred at room temperature under argon for 3 days. The reaction mixture was poured into $200 \mathrm{~mL}$ water containing $1 \mathrm{~mL}$ of concentrated $\mathrm{HCl}$. The polymer was filtered, washed with distilled water, and dried under vacuum at $50^{\circ} \mathrm{C}$ for a day. For the purification, the crude polymer was redissolved in chloroform and reprecipitated in $200 \mathrm{~mL}$ of methanol and then dried under vacuum overnight. Yield: $1.9 \mathrm{~g}$ ( $75 \mathrm{wt} \%)$.

Gold-nanoparticles-embedded PP-g-PEG amphiphilic graft copolymers were obtained in our previous study [28]. Briefly, aqueous stock solutions of $\mathrm{HAuCl}_{4}: 0.1 \mathrm{M}$ and the reducing agent, $\mathrm{NaBH}_{4}(0.1 \mathrm{M})$, were prepared separately. The PP-g-PEG2000 graft copolymer $(0.2 \mathrm{~g})$ was dissolved in $20 \mathrm{~mL}$ of THF. $0.10 \mathrm{~mL}$ of $\mathrm{HAuCl}_{4}$ aqueous solution was added into the polymer solution by vigorously stirring. After 10 min stirring, $0.10 \mathrm{~mL}$ of $\mathrm{NaBH}_{4}$ aqueous solution was added to this mixture, generating a deep red colloidal solution. The solution was stirred 10 more minutes and then was poured into a Petri dish $(\Phi=7 \mathrm{~cm})$, and the solvent was allowed to evaporate leaving a deep red colored thin polymer film. The solvent cast film was washed with methanol and dried under vacuum.

\subsection{Methods}

2.2.1. In Vivo Implantation. The in vivo implantation process was the same with our previous study of Au-nanoparticleembedded biodegradable polyhydroxyoctanoate (PHO) polymer blocks [30]. We have analyzed in vivo behavior of five different polymers, PP as the control group, PP-PEG 2000, PP-PEG-4000, Au-embedded PP-PEG, and Auembedded PP-PEG 4000. Two polymer film samples of five different polymer types were prepared in standard measures as $10 \times 12 \times 0.3 \mathrm{~mm}$ in dimensions, and eight polymer film samples in total were sterilized via ethylene oxide gas for eight hours and implanted to rats in sterile forms. All surgical procedures were done in sterile conditions under the approval of Ethical Committee of Hacettepe University. A mixture of $0.1 \mathrm{~mL} / \mathrm{kg}$ alphasyn and $0.3 \mathrm{~mL} / \mathrm{kg}$ ketamine was used to anaesthetize five different female albino Wister rats in average weight of $250 \mathrm{~g}$. Then, two polymer film samples of each type were embedded into the back of five different rats individually. A $5 \mathrm{~cm}$ midline incision was made under an operating microscope (Zeiss, 3,5*). Each side of the spinous process of the vertebrae was dissected bluntly to create a subcutaneous pocket for the placement of the polymer films. Each polymer film sample was anchored to each side of the back via 7,0 nylon sutures (Ethilon, Ethicon) to prevent displacement.

2.2.2. Graft Harvesting. Grafts were harvested in similar fashion as in our previous study [30]. After 30 days of implantation, all five rats were sacrificed and two polymer samples of the same type attached to the subcutaneous tissue and muscle fascia were harvested from each animal. One polymer sample was kept for SEM assessment, and the other block was immediately fixed in a $10 \mathrm{wt} \%$ formalin solution for several days to keep the structure of the polymer and the surrounding tissue in the harvested from. This procedure was repeated for each sample harvested from the other animals. All five polymer film samples were then embedded in paraffin wax, cut into $5 \mu \mathrm{m}$ thick sections, and stained with hematoxylin-eosin and Mason's trichrome. Under the light microscope, in vivo behavior of each polymer was evaluated.

2.2.3. Histological Observation. Various histological sections from each harvested sample were observed by using an optical microscope with different magnifications. In each histological section, there was a capsule formation in different thickness covering the implanted polymer film sample. In vivo behavior of each polymer sample was discussed via intensity of the inflammatory reaction within this capsule. The inflammatory reaction was categorized in four different groups: inflammatory cell population, collagen synthesis, thickness of the capsule, and new blood vessel formation named as neovascularization. Interpretation of inflammatory reaction for different polymer samples was performed by using a modified scale of Marios et al. [32] which was initially introduced to the literature via our previous study [30]. The thickness of the capsule surrounding the polymer sample was measured from four different standardized areas, one on each side of the implant. The final value was recorded 


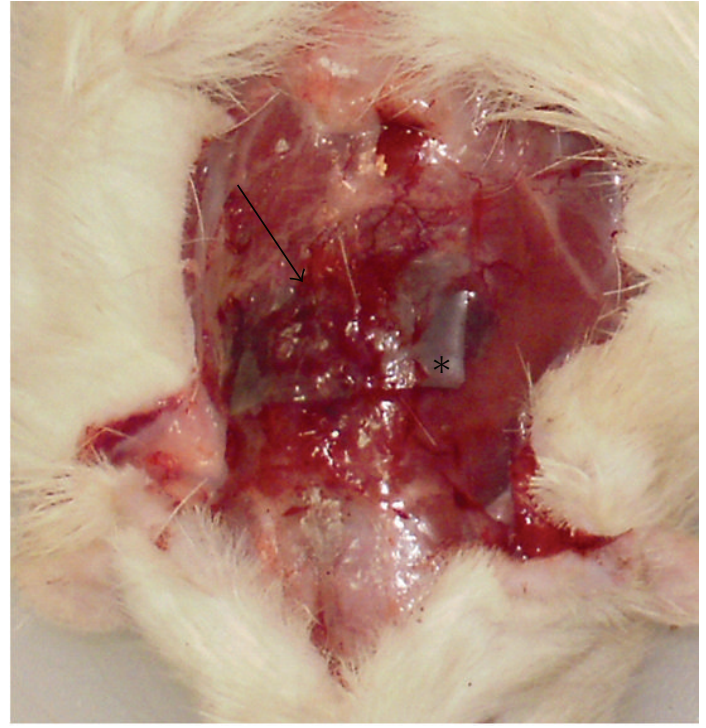

FIGURE 1: In vivo appearance of PP on the 30th day of implantation. There is a thick and hard capsule (black arrow) around the polymer film (asterisk).

as an average of these four different measurements. The collagen proliferation, intensity of neovascularization, and inflammatory cell count were analyzed and scored in the same fashion [33].

2.2.4. SEM Assessment. Scanning electron micrographs of the polymer samples were taken on a JEOL JXA-6335 FS scanning electron microscope (SEM). SemiquantitativeInca-energy dispersive X-ray spectroscopy (EDS) was also used for the assessment of metal nanoparticles. For the fracture surface assessment, the composite polymer samples were frozen under liquid nitrogen then fractured, mounted, and coated with palladium, gold, and carbon. The SEM was operated at $15 \mathrm{kV}$, and the electron images were recorded directly from the cathode ray tube on a Polaroid film.

\section{Results}

In this study, we have compared the in vivo properties and SEM assessment of PP as control group and four different types of amphiphilic graft copolymers: PP-PEG-2000, PPPEG-4000, Au-PP-PEG-2000, and AuPP-PEG-4000. Each polymer film was placed on the back of the rat in similar fashion with our previous studies $[29,30]$. Throughout the implantation period, all the rats were healthy and there were no adverse reaction such as necrosis or abscess formation in the neighborhood of the implants.

3.1. Macroscopic Appearance. Neither of the films had abscess formation or adverse inflammatory reactions neighboring the polymer blocks since all sterilized polymer samples were implanted to rats in sterile condition. PP polymer films were deeply embedded into the soft tissue and there was a thick, hard capsule formation around the sample which was hard to detach from the surrounding tissue (Figure 1). The surrounding tissue seemed to be overriding the polymer film at the edges. However, all other amphiphilic graft copolymers revealed thinner capsule formation than the PP polymer sample. There was a moderate capsule formation around the PP-PEG-2000 polymer film, and the physical appearance of PP-PEG-4000 film was also similar with prominent vascular capsule. On the other hand, Au-PP-PEG-2000 and Au-PP-PEG-4000 both had a very fine capsule which was hardly seen on the polymer. Capsule formation and blood supply of the surrounding tissue did not differ in between high- and low-molecular-weight side chains in both goldnanoparticle-embedded and pure polypropylene polymer blocks. Additionally, the surface of all polymer blocks did not changed macroscopically.

3.2. Histological Assessment. We have analyzed the inflammation around the polymer film with a standard scoring described in our previous study [30]. Soft tissue response of five different polymer blocks was analyzed according to the inflammatory reaction within the capsule (Table 1).

In every aspect of the inflammatory parameters, PP sample (control group) demonstrated the most prominent inflammatory reaction among all samples (Figures $2(a)$ and 2(b)).

Collagen infiltration was intense in PP sample, and the least accumulation was seen in Au-PP-PEG-4000. Neovascularization and inflammatory cell count were less in Au-nanoparticle-containing polymer blocks compared to the $\mathrm{Au}$ free polymers. However, gold-containing polymer blocks appeared to have more foreign-body giant cell count compared to pure PP and PP-PEG polymer blocks. When PP-PEG-2000 and Au-PP-PEG-2000 were compared, neovascularization and inflammatory cell count were lower in gold-nanoparticle-embedded block than the pure ones. Giant cells are lined on the polymer side of the capsule in front of the newly formed vessels (Figure 3(a)).

On the other hand, there was a marked difference in the aspect of inflammation in between high- and low-molecularweight polymer blocks independent of Au nanoparticles. Inflammatory cell reaction in each of the 4000 weighted PEG block copolymer was fairly mild compared to the 2000 weighted PEG. Capsule was thinner with fewer new vessel formations in PP-PEG-4000 polymer blocks. Giant cell accumulation was also prominent in high-molecular-weight block copolymers.

Among all polymer blocks, gold-nanoparticle-embedded polymer film samples were presented with very fine inflammatory reaction. Au-PP-PEG-4000 had the thinnest capsule $(0,060 \mathrm{~mm})$. There was a very few inflammatory cell migration with giant cells in majority around this polymer film sample compared to the Au-PP-PEG-2000 (Figures 3(a) and $3(\mathrm{~b})$ ). New blood vessel formation in thin and loose capsule was seen in both histological sections, more prominent in high-molecular-weight polymer sample (Figure 3(b)).

3.3. SEM Assessment. SEM scans of PP polymer sample revealed no change after 30 days of implantation. In PEGattached polymer samples, whether they are Au attached or not, there were some changes on the surface of the polymer. 
TABLE 1: Histological findings of polymer blocks following 30 days of implantation.

\begin{tabular}{lccccc}
\hline & Collagen infiltration & $\begin{array}{c}\text { Inflammatory cell } \\
\text { count }\end{array}$ & Giant cell & Neovascularization & $\begin{array}{c}\text { Capsule thickness } \\
(\mathrm{mm})\end{array}$ \\
\hline PP (control group) & +++++ & 218 & 14 & +++++ & 1.554 \\
PP-PEG-2000 & +++ & 86 & 8 & +++ & 0.350 \\
Au-PP-PEG-2000 & ++ & 32 & 16 & + & 0.160 \\
PP-PEG-4000 & ++ & 45 & 12 & ++ & 0.210 \\
Au-PP-PEG-4000 & + & 18 & 24 & + & 0.060 \\
\hline
\end{tabular}

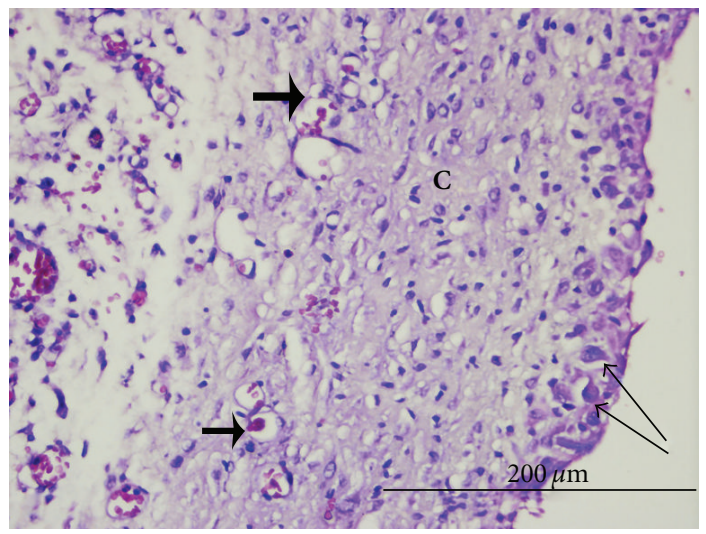

(a)

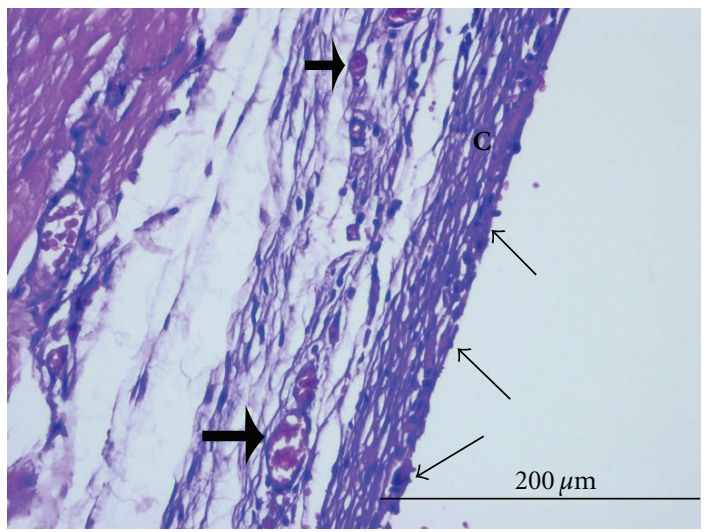

(b)

Figure 2: Histological appearance of PP (a) and PP-PEG-4000 (b) polymers. (H\&E staining, 40x magnification.) Notice thick capsule (C) around pure polypropylene sample compared to graft copolymer. New blood vessels (thick arrow) are in majority in PP, and giant cell (thin arrow) count is prominent in PP-PEG-4000.

In all polymer samples (except from PP sample), there were circular holes on the surface of the polymer with darkened spaces in the periphery. The number of these holes was increased as the molecular weight of the polymer sample increase. Also Au-attached polymer samples contained more holes on the surface than pure graft copolymers. When the Au-PP-PEG-2000 and Au-PP-PEG-4000 were compared, there was a major difference in between (Figure 4(a)). There were multiple holes in various sizes on the surface of Auattached PP-PEG-4000 (Figure 4(b)). Since these holes are two dimensional, one cannot decide whether these are embedded holes or crater-like elevated areas.

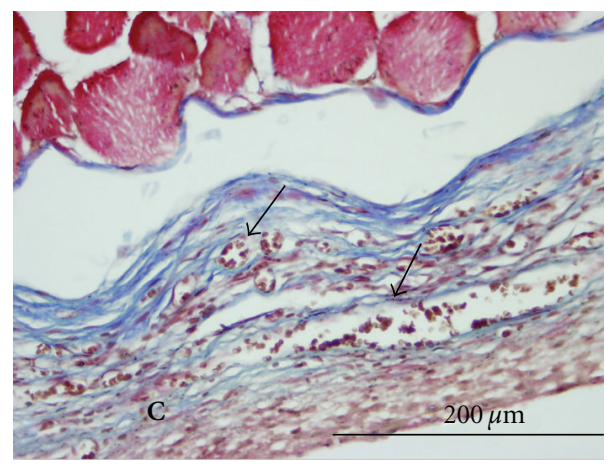

(a)

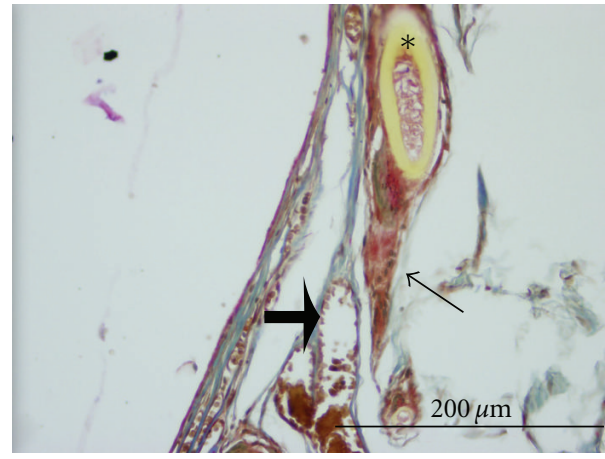

(b)

FIGURE 3: 30th day of implantation of Au-PP-PEG-2000 (a) and Au-PP-PEG-4000 (b). (Mason's Trichrome staining, 40x magnification.) The capsule is thicker with more inflammatory cells and newly formed blood vessels (thin arrow) in Au-PP-PEG-2000 (a), and neovascularization (thick arrow) and giant cell accumulation (thin arrow) is more prominent in histological section of Au-PPPEG-4000 (b).

The same appearance was present in the light microscopic section of the Au-attached polymer (Figures 5(a) and 5(b)). In both cases, this appearance shows that there is major structural defect in implanted polymer block and this property might be the result of drying process of the swollen PEG blocks of the graft copolymer.

\section{Discussion}

Polypropylene (PP) is a widely used polymer in medical field. Since it is an unbreakable, elastic, and hydrophobic polymer and causes strong chronic inflammatory reaction, $\mathrm{PP}$ is a good substitute to reinforce weakened soft tissue, 


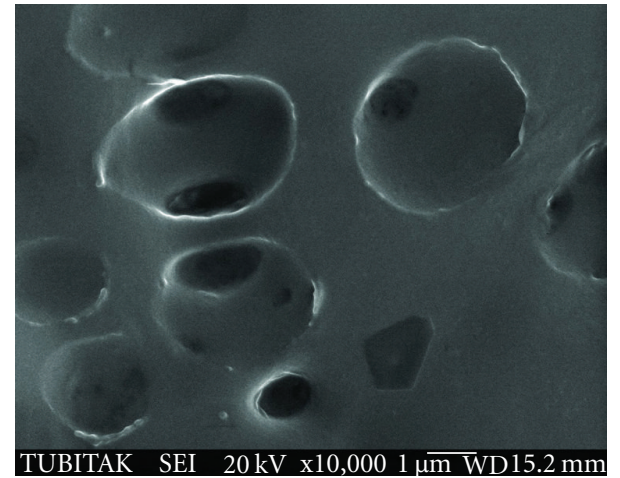

(a)

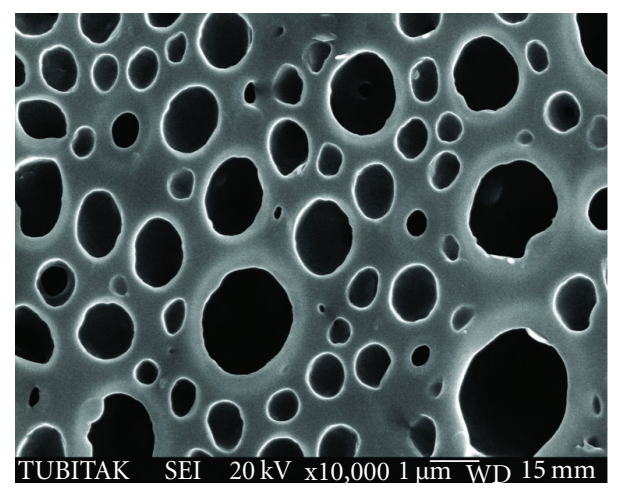

(b)

FIGURE 4: SEM analysis of Au-PP-PEG-2000 (a) and Au-PP-PEG4000 (b) on the 30th day of implantation (10,000x magnification). There are multiple depressed circular areas on surface of Au-PPPEG-2000. These areas are transformed into "punched holes" in Au-PP-PEG-4000.

for example, inguinal or incisional hernias, abdominal wall or pelvic floor defects $[34,35]$. However, its hydrophobicity and potent foreign-body reaction limit its other medical applications such as drug carriers or vascular grafts [36]. In order to overcome these deficiencies and to broaden its medical applications, one approach is to prepare block copolymers containing hydrophilic blocks that can modify the hydrophilicity, crystallinity, mechanical properties, and biocompatibility of the original material [37]. In this regard, polyethylene glycol (PEG) can be used as it is a popular hydrophilic and biocompatible polymer. It has been shown that PEG-grafted copolymers have the ability to reduce platelet adhesion and bacterial repulsion [38].

Furthermore, nanoparticles especially gold nanoparticles embedded into the polymer structure were reported to enhance the biocompatibility and the antimicrobial effect of the polymer itself $[28,30]$. Therefore, PP can be modified to form a more biocompatible and antimicrobial polymer for in vivo applications via attaching gold nanoparticles and PEG side chains. In our previous report, we have already described the synthesis and characterization of nanoparticles embedded into amphiphilic comb-type graft copolymers [28]. A question may rise whether in vivo properties of the copolymer may be enhanced as the number of side chain attached to the original polymer increases. Therefore, in this present

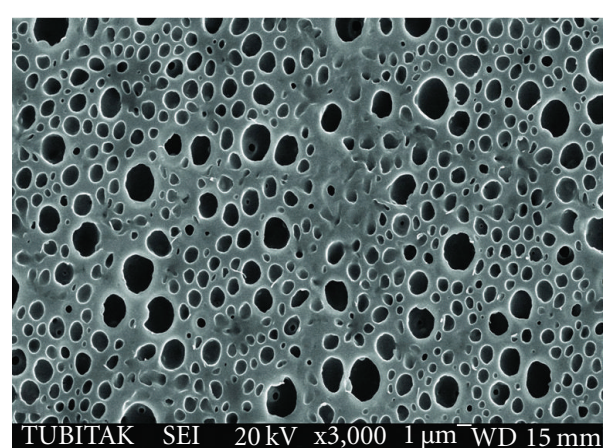

(a)

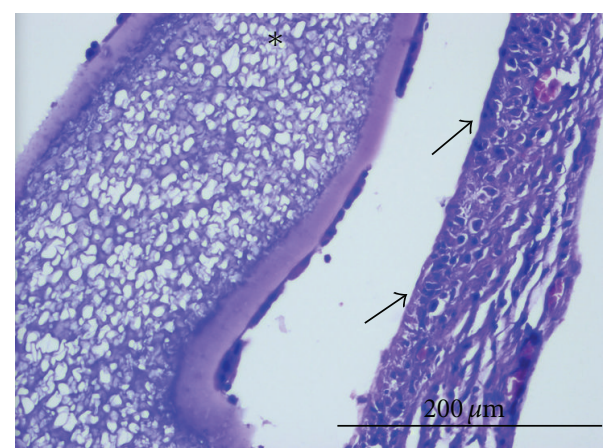

(b)

FIgURe 5: (a) SEM analysis of Au-PP-PEG-4000 on 30th day (3000x magnification) and (b) histological section of Au-PP-PEG-4000 on 30th day of implantation (H\&E, 20x magnification). Multiple punched holes are seen in both SEM section and histological section.

study, we have compared the soft tissue response of the pure PP polymer samples with gold-nanoparticle-embedded PPPEG copolymers and pure type PP-PEG block copolymers in two different molecular weight forms following in vivo application via histochemical and SEM assessment.

Inflammatory cells such as polymorph nuclear cells and giant cells play an important role in the foreign-body reaction for any material implanted to living organism. These cells are carried to the reaction site via newly formed vessels [39, 40]. PP had the most intense inflammatory reaction with highest inflammatory cell count and multiple blood vessels among all other polymer samples. When the number of PEG side chains is attached (PP-PEG-4000), the inflammatory cells and collagen accumulation decrease and the sample becomes more biocompatible (Table 1). Similar to our previous study [30], soft tissue response of the goldnanoparticle-attached polymer blocks is found to be milder with lower cellular migration and less collagen formation. Au-PP-PEG-4000 had the thinnest capsule formation with least cellular count (Figure 3(b)). These data indicate that both addition of gold nanoparticles and increasing the number of side chains in the block copolymer will facilitate the in vivo compatibility of the polymer itself.

PP-PEG-2000 and Au-PP-PEG-2000 seemed to have similar SEM scans, with minor superiority in number of holes 
in Au-embedded copolymers. However, gold-nanoparticlesembedded high-molecular-weight polymer block showed unexpected properties. There were multiple craters like holes on the surface of the polymer, and this appearance was also present in the light microscopic sections (Figures 5(a) and 5(b)). In first glance these multiple punched holes are thought to be formed with the drying process of the SEM assessment. Interestingly, similar appearance is seen on the light microscopic sections without passing through any drying process. Since these holes are present on the surface of the high-molecular-weight polymer blocks, they might be formed by the hydrophilic side chains. These hydrophilic PEG side chains attract the water in the microenvironment of the implantation area, and small blebs occur on the surface of the polymer. As the number of hydrophilic and biodegradable PEG side chains increases, the polymer absorbs more water and the number of crater-like holes on the surface of the polymer increases as well. This property changes the soft tissue response of the PP polymer in favor of milder inflammatory reaction.

\section{Conclusion}

We have investigated in vivo behavior of PP, PP-g-PEG2000, PP-g-PEG4000, AuPP-g-PEG2000, and AuPP-g-PEG4000 after 30 days of implantation and compared the inflammatory reaction and SEM assessment of each of them. Overall, Au-embedded polymer favors less inflammatory reaction when compared to pure PP-g-PEG ones, and even more increased molecular weight of the polymer film with increased number of side chains of PEG reveals milder inflammatory reaction compared to the low-molecularweight ones. SEM assessment also supports this data with a lot of holes on the surface of Au-PP-g-PEG 4000. However, featuring studies should be done to understand why these holes are present on the surface of the polymer after the in vivo implantation.

\section{Abbreviations}

PP-g-PEG: Polypropylene-g-poly(ethylene glycol)

Au-PP-g-PEG: Au-nanoparticle-embedded

$\begin{array}{ll} & \text { Polypropylene-g-poly(ethylene glycol) } \\ \text { PP: } & \text { Polypropylene } \\ \text { SEM: } & \text { Scanning electron microscopy } \\ \text { THF: } & \text { Tetrahydrofuran } \\ \text { PEG: } & \text { Poly(ethylene glycol) } \\ \text { PHO: } & \text { Polyhydroxyoctanoate. }\end{array}$

\section{Conflict of Interests}

The authors declare that they have no competing interests.

\section{References}

[1] Y. Koike and M. Cakmak, "Atomic force microscopy observations on the structure development during uniaxial stretching of PP from partially molten state: effect of isotacticity," Macromolecules, vol. 37, no. 6, pp. 2171-2181, 2009.
[2] K. H. Lee, O. Ohsawa, K. Watanabe et al., "Electrospinning of syndiotactic polypropylene from a polymer solution at ambient temperatures," Macromolecules, vol. 42, no. 14, pp. 5215-5218, 2009.

[3] H. Macit and B. Hazer, "Grafting on polybutadiene with polytetrahydrofuran macroperoxyinitiators. Postpolymerization studies," European Polymer Journal, vol. 43, no. 9, pp. 38653872, 2007.

[4] D. Neugebauer, Y. Zhang, T. Pakula, S. S. Sheiko, and K. Matyjaszewski, "Densely-grafted and double-grafted PEO brushes via ATRP. A route to soft elastomers," Macromolecules, vol. 36, no. 18, pp. 6746-6755, 2003.

[5] N. Hadjichristidis, M. Pitsikalis, S. Pispas, and H. Iatrou, "Polymers with complex architecture by living anionic polymerization," Chemical Reviews, vol. 101, no. 12, pp. 37473792, 2001.

[6] G. Cheng, A. Böker, M. Zhang, G. Krausch, and A. H. E. Müller, "Amphiphilic cylindrical core-shell brushes via a "grafting from” process using ATRP," Macromolecules, vol. 34, no. 20, pp. 6883-6888, 2001.

[7] H. Arslan, N. Yesilyurt, and B. Hazer, "Brush type copolymers of poly(3-hydroxybutyrate) and poly(3-hydroxyoctanoate) with same vinyl monomers via "grafting from" technique by using atom transfer radical polymerization method," Macromolecular Symposia, vol. 269, pp. 23-33, 2008.

[8] M. Q. Chen, T. Serizawa, and M. Akashi, "Graft copolymers having hydrophobic backbone and hydrophilic branches. XVI. Polystyrene microspheres with poly(N-isopropylacrylamide) branches on their surfaces: size control factors and thermosensitive behavior," Polymers for Advanced Technologies, vol. 10, no. 1-2, pp. 120-126, 1999.

[9] N. Hadjichristidis, H. Iatrou, M. Pitsikalis, and J. Mays, "Macromolecular architectures by living and controlled/living polymerizations," Progress in Polymer Science, vol. 31, no. 12, pp. 1068-1132, 2006.

[10] M. Zhang and A. H. E. Müller, "Cylindrical polymer brushes," Journal of Polymer Science, Part A: Polymer Chemistry, vol. 43, no. 16, pp. 3461-3481, 2006.

[11] B. Lessard and M. Marić, "Nitroxide-mediated synthesis of poly(poly(ethylene glycol) acrylate) (PPEGA) comb-like homopolymers and block copolymers," Macromolecules, vol. 41, no. 21, pp. 7870-7880, 2008.

[12] M. Balci, A. Alli, B. Hazer, O. Güven, K. Cavicchi, and M. Cakmak, "Synthesis and characterization of novel comb-type amphiphilic graft copolymers containing polypropylene and polyethylene glycol," Polymer Bulletin, vol. 64, no. 7, pp. 691705, 2010.

[13] T. Pakula, Y. Zhang, K. Matyjaszewski et al., "Molecular brushes as super-soft elastomers," Polymer, vol. 47, no. 20, pp. 71987206, 2006.

[14] G. Zhou and J. Smid, "Micellization of amphiphilic star polymers with poly(ethylene oxide) arms in aqueous solutions," Langmuir, vol. 9, no. 11, pp. 2907-2913, 1993.

[15] A. Sundararaman, T. Stephan, and R. B. Grubbs, "Reversible restructuring of aqueous block copolymer assemblies through stimulus-induced changes in amphiphilicity," Journal of the American Chemical Society, vol. 130, no. 37, pp. 12264-12265, 2008.

[16] I. Gitsov, K. L. Wooley, C. J. Hawker, P. T. Ivanova, and J. M. J. Fréchet, "Synthesis and properties of novel linear-dendritic block copolymers. Reactivity of dendritic macromolecules toward linear polymers," Macromolecules, vol. 26, no. 21, pp. 5621-5627, 1993. 
[17] S. Förster and M. Antonietti, "Amphiphilic block copolymers in structure-controlled nanomaterial hybrids," Advanced Materials, vol. 10, no. 3, pp. 195-217, 1998.

[18] N. Hadjichristidis, M. Pitsikalis, S. Pispas, and H. Iatrou, "Polymers with complex architecture by living anionic polymerization," Chemical Reviews, vol. 101, no. 12, pp. 37473792, 2001.

[19] J. E. Millstone, S. J. Hurst, G. S. Métraux, J. I. Cutler, and C. A. Mirkin, "Colloidal gold and silver triangular nanoprisms," Small, vol. 5, no. 6, pp. 646-664, 2009.

[20] J. Shan and H. Tenhu, "Recent advances in polymer protected gold nanoparticles: synthesis, properties and applications," Chemical Communications, no. 44, pp. 4580-4598, 2007.

[21] M. A. El-Sayed, "Some interesting properties of metals confined in time and nanometer space of different shapes," Accounts of Chemical Research, vol. 34, no. 4, pp. 257-264, 2001.

[22] R. Oren, Z. Liang, J. S. Barnard, S. C. Warren, U. Wiesner, and W. T. S. Huck, "Organization of nanoparticles in polymer brushes," Journal of the American Chemical Society, vol. 131, no. 5, pp. 1670-1671, 2009.

[23] B. J. Kim, J. Bang, C. Hawker, and E. J. Kramer, "Effect of areal chain density on the location of polymer-modified gold nanoparticles in a block copolymer template," Macromolecules, vol. 39, no. 12, pp. 4108-4114, 2006.

[24] C. S. Warren, L. C. Messina, L. S. Slaughter et al., "Ordered mesoporous materials from metal nanoparticle-block copolymer self-assembly," Science, vol. 320, no. 5884, pp. 1748-1752, 2008.

[25] J. J. Chiu, B. J. Kim, E. J. Kramer, and D. J. Pine, "Control of nanoparticle location in block copolymers," Journal of the American Chemical Society, vol. 127, no. 14, pp. 5036-5037, 2005.

[26] C. Aymonier, U. Schlotterbeck, L. Antonietti et al., "Hybrids of silver nanoparticles with amphiphilic hyperbranched macromolecules exhibiting antimicrobial properties," Chemical Communications, vol. 8, no. 24, pp. 3018-3019, 2002.

[27] V. A. Mallia, P. K. Vemula, G. John, A. Kumar, and P. M. Ajayan, "In situ synthesis and assembly of gold nanoparticles embedded in glass-forming liquid crystals," Angewandte Chemie, vol. 46, no. 18, pp. 3269-3274, 2007.

[28] O. A. Kalayci, F. B. Cömert, B. Hazer, T. Atalay, K. A. Cavicchi, and M. Cakmak, "Synthesis, characterization, and antibacterial activity of metal nanoparticles embedded into amphikphilic comb-type graft copolymers," Polymer Bulletin, vol. 65, no. 3, pp. 215-226, 2010.

[29] D. B. Hazer, B. Hazer, and F. Kaymaz, "Synthesis of microbial elastomers based on soybean oily acids: biocompatibility studies," Biomedical Materials, vol. 4, no. 3, article 035011, 2009.

[30] D. B. Hazer and B. Hazer, "The effect of gold clusters on the autoxidation of poly(3-hydroxy 10-undecenoate-co-3hydroxy octanoate) and tissue response evaluation," Journal of Polymer Research, vol. 18, no. 2, pp. 251-262, 2011.

[31] B. Çakmakli, B. Hazer, I. Ö. Tekin, Ş. Açikgöz, and M. Can, "Polymeric linoleic acid-polyolefin conjugates: cell adhesion and biocompatibility," Journal of the American Oil Chemists' Society, vol. 84, no. 1, pp. 73-81, 2007.

[32] Y. Marois, Z. Zhang, M. Vert, L. Beaulieu, R. W. Lenz, and R. Guidoin, "In vivo biocompatibility and degradation studies of polyhydroxyoctanoate in the rat: a new sealant for the polyester arterial prosthesis," Tissue Engineering, vol. 5, no. 4, pp. 369-386, 1999.
[33] W. F. A. Den Dunnen, P. H. Robinson, R. van Wessel, A. J. Pennings, M. B. M. van Leeuwen, and J. M. Schakenraad, "Longterm evaluation of degradation and foreign-body reaction of subcutaneously implanted poly(DL-lactide- $\varepsilon$-caprolactone)," Journal of Biomedical Materials Research, vol. 36, no. 3, pp. 337-346, 1997.

[34] H. Kodo, Y. Hanada, M. Ikeda, K. Ohta, and N. Tamaki, "Polypropylene mesh substitute for the fasial defect after using for the Dural repair," Medical Chiropractic Neurology, vol. 40, pp. 77-80, 2000.

[35] R. Hiltunen, K. Nieminen, T. Takala et al., "Low-weight polypropylene mesh for anterior vaginal wall prolapse: a randomized controlled trial," Obstetrics and Gynecology, vol. 110, no. 2, pp. 455-462, 2007.

[36] H. Scheidbach, C. Tamme, A. Tannapfel, H. Lippert, and F. Köckerling, "In vivo studies comparing the biocompatibility of various polypropylene meshes and their handling properties during endoscopic total extraperitoneal (TEP) patchplasty: an experimental study in pigs," Surgical Endoscopy and Other Interventional Techniques, vol. 18, no. 2, pp. 211-220, 2004.

[37] Z. Li, S. Cheng, S. Li, Q. Liu, K. Xu, and G. Q. Chen, "Novel amphilic poly ( eser-urethane)s based on poly-R-3-hydroxyalkanoates. Synthesis, biocompatibility and aggregation in aqueous solution," Polymer International, vol. 57, no. 6, pp. 887-894, 2008.

[38] X. Li, X. J. Loh, K. Wang, C. He, and J. Li, "Poly(ester urethane)s consisting of poly[(R)-3-hydroxybutyrate] and poly(ethylene glycol) as candidate biomaterials: characterization and mechanical property study," Biomacromolecules, vol. 6, no. 5, pp. 2740-2747, 2005.

[39] X. H. Qu, Q. Wu, K. Y. Zhang, and G. Q. Chen, "In vivo studies of poly(3-hydroxybutyrate-co-3-hydroxyhexanoate) based polymers: biodegradation and tissue reactions," Biomaterials, vol. 27, no. 19, pp. 3540-3548, 2006.

[40] A. Baykal, D. Onat, K. Rasa, N. Renda, and I. Sayek, "Effects of polyglycolic acid and polypropylene meshes on postoperative adhesion formation in mice," World Journal of Surgery, vol. 21, no. 6, pp. 579-583, 1997. 


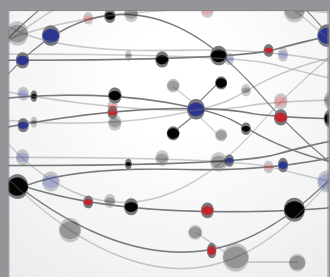

The Scientific World Journal
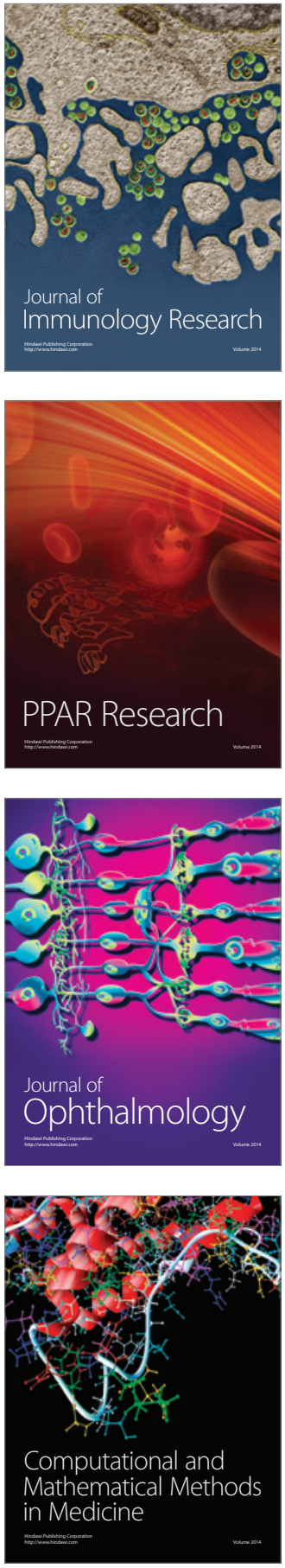

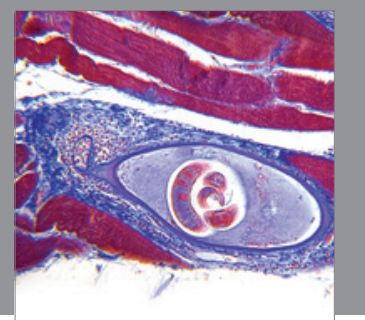

Gastroenterology

Research and Practice
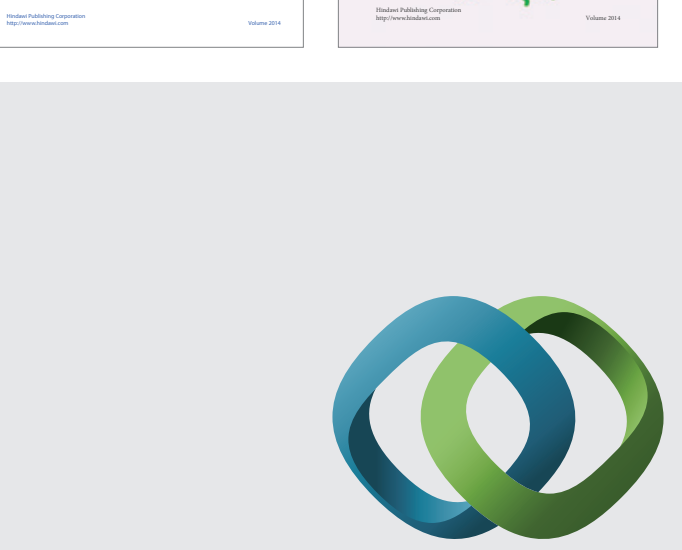

\section{Hindawi}

Submit your manuscripts at

http://www.hindawi.com
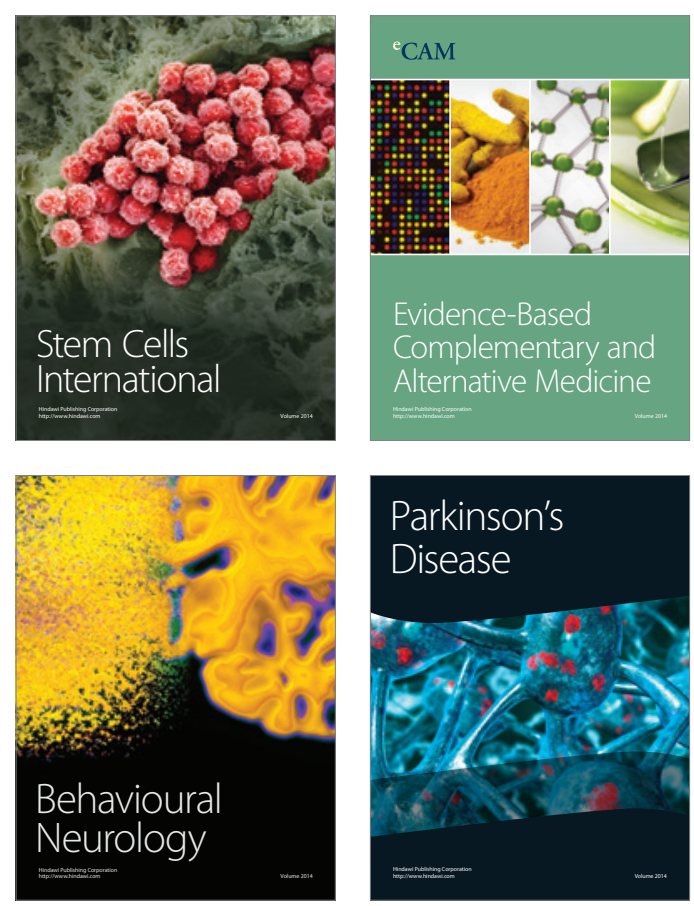

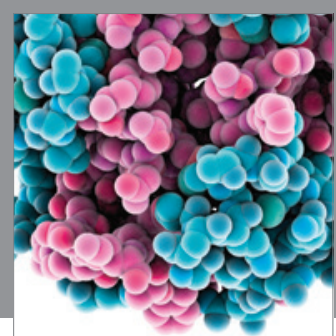

Journal of
Diabetes Research

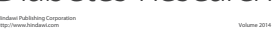

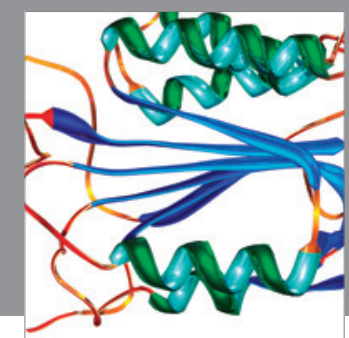

Disease Markers
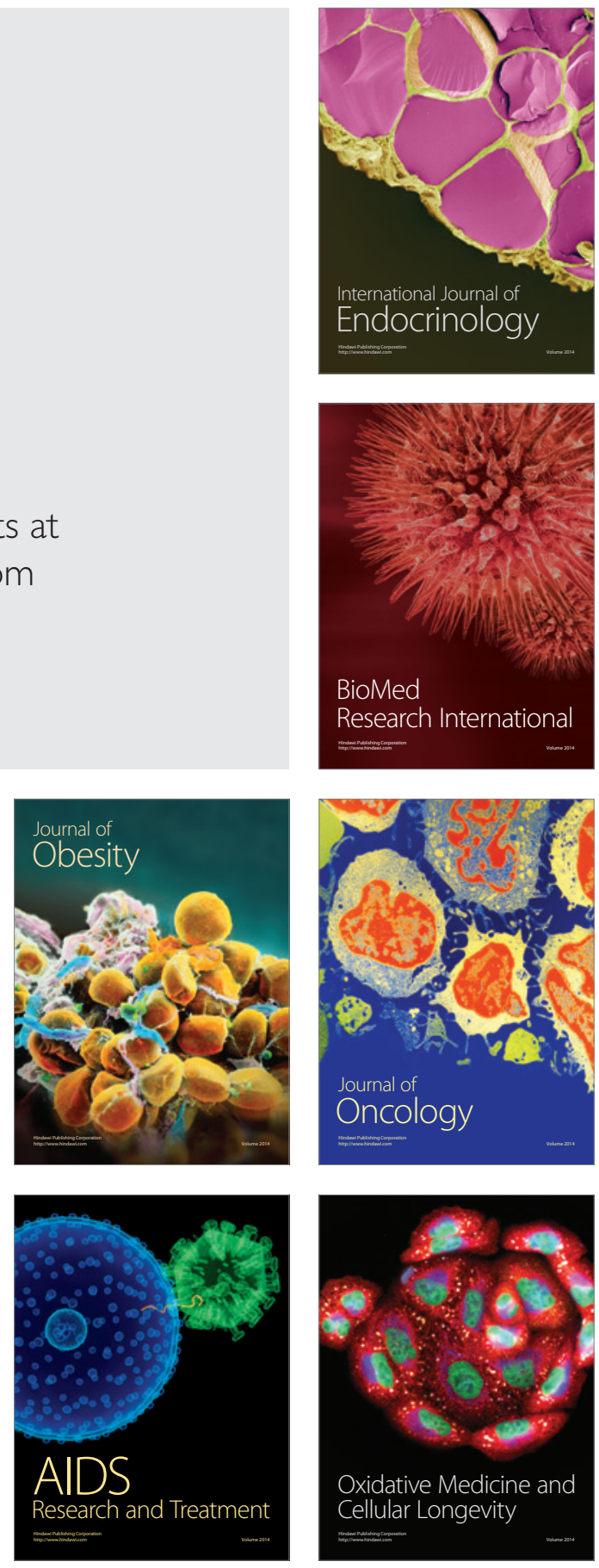